\title{
Community-based nursing education
}

\section{Toplum temelli hemşirelik eğitimi}

\author{
Sevim Ulupınar ${ }^{1}$ \\ Emine Gürel ${ }^{2}$ \\ Emine Şenyuva ${ }^{3}$ \\ Hülya Kaya ${ }^{4}$
}

\section{Özet}

Günümüzde sağllk hizmetlerinin önemli bir bölümü toplum temelli ortamlarda verilmektedir. Bu ortamlarda çalışacak nitelikte sağlık insan gücü yetiştirmek için kullanılan en etkin yöntemlerden biri toplum temelli eğitim programlarıdır. Türkiye'de hemşire yetiştiren eğitim kurumlarının programlarında toplum temelli eğitime kısmen yer verildiği ancak toplum temelli eğitim programlarının olmadığ1 görülmüştür. Ülkemizin yüz yüze kaldığı ciddi bir sorun olan göç ve göçmenlerin sağlik ihtiyaçları, nüfusun yaşlanması ve buna eşlik eden sağllk sorunları, kronik hastalıklarla mücadele ve benzeri sorunların çözümünde rol alacak nitelikli sağlık insan gücünün yetiştirilmesinde etkin ve kalıcı bir çözüm olarak toplum temelli eğitim programlarının gündeme alınması zorunlu hale gelmektedir. Derlemenin temel amac1, toplumun ihtiyaçlarına uygun nitelikte hemşire yetiştirmek için toplum temelli hemşirelik eğitim programlarının önemini ve programın temel özelliklerini açıklamaktır. Derlemede, toplum temelli eğitim kavramı, toplum temelli hemşirelik eğitimi programı uygulamaları, programın güçlü yönleri ve

\footnotetext{
1 Associate Professor, Istanbul University -Cearrahpasa, Florence Nightingale Faculty of Nursing, Department of Education in Nursing, sevim.ulupinar@istanbul.edu.tr

2 Ph.D. Student in Nursing Education Department, Istanbul University - Cerrahpasa Graduate School of Education, eminemgurel@gmail.com

3 Associate Professor, Istanbul University -Cearrahpasa, Florence Nightingale Faculty of Nursing, Department of Education in Nursing, esenyuva@istanbul.edu.tr

${ }_{4}^{4}$ Professor, Istanbul University -Cearrahpasa, Florence Nightingale Faculty of Nursing, Department of Education in Nursing, hulyakay@istanbul.edu.tr
} 
strengths and difficulties of the program, basic principles to be considered while preparing community based education program are examined.

Keywords: Community-based community-based nursing curriculum.

(Extended English summary is at the end of this document) yaşanan güçlükler, toplum temelli eğitim programı hazırlanırken dikkat edilmesi gereken temel ilkeler incelenmiştir.

Anahtar Kelimeler: Toplum temelli eğitim; toplum temelli hemşirelik eğitimi; eğitim education; toplum
education; programi.

\section{Giriş}

Dünya Sağlık Örgütü’nün (DSÖ) 1978 yllında Alma Ata Bildirgesi'nde "Herkes İçin Sağlık" hedeflerini açıklamasıyla, dünya ülkeleri birinci basamak sağlık hizmetleri ile ilgili sağlık politikaları geliştirmeye başlamışlardır (Harden, Sowden \& Dunn, 1984). Sağllk hizmetleri finansmanındaki değişim ve maliyet etkin politikalar; hastanede yatış endikasyonlarını azaltmış, hastanede kalış süresini kısaltmış, hastanelerin yeniden yapılandırılarak küçültülmesine yol açmıştır. Bu gelişmeler sağlık hizmetlerinin sunumunu, akut bakım verilen büyük eğitim ve araştırma hastanelerinden, ayaktan hizmet verilen, hastane olmayan toplum temelli ortamlara doğru dönüştürmüştür (Cauley ve ark, 2001; Ervin ve ark, 2006; Oneha, Yoshimoto, Bell, \& Enos, 2001; Van Ort \& Townsend, 2000). Sağlık eğitim politikaları ve sağlık çalışanlarının eğitimi, sağlık politikaları ve finansmanında yaşanan değişimlerden doğrudan etkilenmekte ve değişen bu politikaların gerektirdiği, toplumun ihtiyaçlarını karşılayabilecek nitelikte sağlık çalışanı yetiştirme arayışını beraberinde getirmektedir (Cauley ve ark, 2001). Sağlık insan gücü yetiştiren yükseköğretim kurumları, bu hedeflere yönelik bir yaklaşım olan toplum temelli sağlık eğitimi uygulamalarını 20-30 yıldan beridir kullanmaktadır.

Eğitimin hedefleri, birey ve meslek grubu üyelerinin içinde yaşadığ1 toplumu fizyolojik, psikolojik, sosyolojik, çevresel, ekonomik ve politik boyutları ile değerlendirerek toplumsal sorunları tanımlayan, anlamlandıran, analiz eden, gerçekçi ve uygulanabilir çözüm önerileri geliştiren, geliştirdiği bu çözümleri toplumun özelliklerini ve gereksinimlerini dikkate alarak uygulayan, değerlendiren ve sonuçlar doğrultusunda gerekli değişiklikleri yapan bireyler yetiştirmektir. Bu hedeflere uygun niteliklere sahip, eleştirel düşünme ve organizasyon becerisi gelişmiş bireylerin yetiştirilmesi için kullanılacak en etkin yaklaşımlardan biri toplum temelli eğitimdir (Carter ve ark, 2005; Owens \& Wang, 1996). Derlemede, toplumun ihtiyaçlarına uygun nitelikte hemşire yetiştirmek için toplum temelli eğitim programlarının önemi ve temel özellikleri, toplum temelli hemşirelik eğitim programı uygulamaları, programın güçlü yönleri ve uygulamada yaşanan güçlükler, toplum temelli bir eğitim programı hazırlanırken dikkat edilmesi gereken temel ilkeler ele alınmıstır.

\section{Toplum Temelli Eğitim}

Toplum temelli eğitim (TTE); öğrencilere yeni öğrendikleri akademik bilgi ve becerileri gerçek yaşam durumlarında kullanma firsatı veren, öğrenim deneyimlerini sınıf dışına, topluma taşıyan, öğrencilerin öğrenme ve gelişimlerini sağlarken toplumun ihtiyaçlarını karşılayan, öğrenme deneyimlerinin koordinasyonunu eğitim kurumları ve toplumun birlikte üstlendiği eğitim modelidir. TTE'de öğrenme deneyimleri toplumsal ortamlarda gerçekleşir. Öğrenme çevresi, toplumun bulunduğu (kent, kırsal alan vb.) her yerdir. Eğitimciler ve öğrenciler kadar eğitim kurumları, aileler, toplum liderleri, yöneticiler, topluma hizmet veren kurum ve kuruluşlar ve toplumu oluşturan diğer bireyler de T'TE'nin ayrılmaz parçalarıdır ve eğitim programlarının uygulanmasına aktif olarak katıllurlar (Carter ve ark, 2005; Owens \& Wang, 1996, Mekelle University, ty; Villani \& Atkins, 2000; 

16(3), 700-711. doi:10.14687/jhs.v16i3.5514

WHO, 1987; Wink, 2003). T'TE, öğrencilerin yaşadığ1 toplumun ihtiyaçlarını fark etmesine, bu ihtiyaçları karşılamak için sorumluluk almasına ve yeterli olmasına odaklanır. TTE, öğrencilerin bilgiyi kullanma, problem çözme, kişiler arası ilişkiler, yaratıcılık vb. bilişsel, duyuşsal ve sosyal yönlerinin gelişimini amaçlar (Villani \& Atkins, 2000).

Toplum temelli eğitim (community-based education) ile topluma yönelik eğitim (communityoriented education) birbirinin yerine kullanılmakla birlikte farklı kavramlardır. Topluma yönelik eğitim (TYE), sağlık çalışanlarının toplumun öncelikli sağlık sorunları hakkında sağlığın geliştirilmesi ve hastalıkların önlenmesine odaklanılarak eğitilmesidir. TYE, hastalık odaklı değil sağlı̆̆a odaklı sağlık çalışanı yetiştirmeyi amaçlar (Hamad, 1991). Öğrenme süreçlerinin toplum içinde gerçekleşmesi gerekmez. Eğitim üniversite, toplum ve diğer tüm ortamlarda verilebilir ve uzaktan eğitim ile de geliştirilebilir. Ancak öğrenme, toplum ortamlarında gerçekleşiyor ve sadece öğrenci değil toplum temsilcileri, ilgili sektörler, üniversite ve sağlık hizmeti veren kurumların öğrenme sürecine aktif katılımı sağlanıyorsa bu kavram T'TE'ye dönüşür. (Bor, 2003; Talaat, Khamis \& Aziz, 2011). TYE, toplum istekleri doğrultusunda toplumun ihtiyaçlanına göre şekillenirken TTE ise eğitim kurumları ve öğrencilerin gereksinimlerini dikkate alır (Bellack, 1998). TTE'yi TYE'den ayıran özellikler; öğrenmenin gerçekleştiği ortam, öğrenme deneyimlerinin erken dönemde ve toplum temelli ortamlarda başlaması, toplum temelli öğrenme deneyiminin eğitim programı içindeki ağırlı̆̆ı, akademik kurumlarla sağlık hizmet sektörü ve toplum arasında işbirliği olmasıdır (Mtshali, 2005).

Hastanelerde, akut bakım ortamlarında birey tıbbi olarak tanılanmış ve ailesinden ayrılmıştır. Çevre, kurum tarafindan kontrol altına alınmış, ailenin bireyin yanında olması ve bireyin özgürlüğü kısıtlanmıştır. Sağlık ve hastalık birbirinden ayrı kavramlar olarak görülmekte, hastalığın tedavi edilmesine odaklanılmakta ve hastalar kimi zaman nesneleştirilerek "vaka" olarak değerlendirilebilmektedir. Birey hastaneden taburcu olduğunda akut bakım hizmetinin amaçlarının başarılmış olduğu kabul edilmektedir. Toplum temelli uygulamalarda, birey kendi doğal çevresinde aile ve toplumla birliktedir. Hastalık, hayatın bir parçası olarak görülmektedir. Öğrenciler, hastaların poliklinikten hastaneye, hastaneden kendi aile ve sosyal çevresine kadar tüm süreçlerde hastalığını yönetme becerisini izleme firsatı bulurlar (Hunt, 2013, s:16; Kelly, Walters \& Rosenthal, 2014). TTE uygulamalarında, hastanenin toplumun bir parçası olduğu ancak tüm toplumu oluşturmadığı bu nedenle hastane temelli eğitimin TTE'nin bir parçası olarak değerlendirilemeyeceği vurgulanmaktadır (Talaat ve ark, 2011; Hamad, 1991).

\section{Toplum temelli eğitimin güçlï yönleri}

- Sağlık sistemi ve sunulan sağlık hizmetleri hakkında öğrencilere farkındalık kazandırır,

- Değișen ve gelişen sağllk sisteminin gereklerine uyum sağlayan, toplumun sağlık bakım gereksinimlerini bilen meslek üyeleri yetiştirir,

- Sağlıktan hastalığa doğru sürekli bakım anlayışı geliştirir,

- Holistik/bütüncül bakış açısı geliştirilmesini sağlar,

- Öğrencilerin sağlık bakım hizmeti verdikleri sağlıklı ve hasta birey ve ailesini kendi yaşadı̆̆ı sosyal ortam içinde görerek sağlığın sosyal belirteçlerinin sağlık ve toplum sağlığı üzerine etkilerini anlamasını, öncelikli toplum sağlığı sorunlarını belirlemesini, koruyucu ve sağlığ1 geliştirici uygulamaların önemini kavramasını sağlar,

- Farklı toplum temelli ortamlarda geniş ölçekli ve çeşitli öğrenme firsatları sunar,

- Sağlık hizmetlerinin multi-disipliner ekip yaklaşımı ile gerçekleştirilmesini sağlar,

- Bireyleri hasta olarak değil, kendi sağlikları konusunda sorumluluk alan ve kontrol sağlayan bir otorite, sağlık ekibinin bir üyesi olarak görür,

- Öğrencilerin mesleki bilgi, beceri kazanmasının yanı sıra sosyalleşmesini, kültürel farkındalık, sosyal sorumluluk, Özgüven, otonomi, liderlik davranışı, etkili iletişim, sosyal ve organizasyonel beceri, kaynakları etkin ve verimli kullanma becerisi, klinik sonuçlar açısından 
kişisel ve kurumsal hesap verebilirlik, sosyal adalet sorunları ve bunların sağlık üzerine etkileri konusunda daha ileri düzeyde bir anlayış geliştirmesini sağlar,

- Öğrencilerin mezuniyet sonrası uzak ve kaynakları yetersiz bölgelerde görev almak için istekli olmalarını sağlar,

- Öğrencilerin toplum içinde bulunmaları, öğrenme çağındaki bireyler için motivasyon kaynağı ve rol-model olmalarını sağlar. Özellikle eğitime yatırım yapmayan ve kız çocukların eğitimleri ile ilgili isteksiz olan ailelerin bakış açılarını değiştirmelerine katkıda bulunur (Amalba, Mook, Mogre \& Scherpbier, 2016; Bellack, 1998; Carter ve ark, 2005; Davidson, 2002; Dickson, Morris \& Gable, 2015; Edwards, Smith, Courtney, Finlayson, \& Chapman, 2004; Hamad, 1991; Hosny, Kamel, El-Wazir \& Gilbert, 2013; Howe, 2002; Kelly ve ark, 2014; Mabuza ve ark, 2013; Mekelle University, ty; Mtshali \& Gwele, 2016; Oneha ve ark, 2001; Okayama \& Kajii, 2011; Proctor ve ark, 2010),

TTE, sadece öğrenci ve eğitim kurumlarının öğrenme hedeflerine ulaşmasını değil aynı zamanda topluma karşı sosyal sorumluluk görevlerini de yerine getirmelerini sağlar. TTE'de öğrenci, eğitim kurumları, sağlık kurumları ve toplum karşılıklı etkileşerek birbirlerinden öğrenirler. Sağlık hizmeti sunucuları ve akademik kurum etkileşimi, sistemdeki sağlık hizmeti verenlerin bilgilerini güncel tutmalarını sağlar. Bu süreç, bilgi ve beceri kazandırarak toplumun özgüven ve özerkliğinin artmasına, toplumun güçlendirilmesine, tıbbi bakıma ilişkin olumsuz düşüncelerin ortadan kaldırılmasına, sağlık hizmeti verilen kuruluşlardaki iş yükünün azaltılmasına, hizmetin kalitesinin artmasına katk1 sağlar (Carter ve ark, 2005; Edwards ve ark, 2004; Linda, Mtshali \& Engelbrecht, 2013. Mabuza ve ark, 2013; Marcus, Taylor, Hormann, Walker \& Carroll, 2011; Mtshali, 2011; Mtshali \& Gwele, 2016; Nambozi \& Locsin, 2017).

\section{Toplum temelli eğitimde yaşanan güclükler}

- TTE kavramı ve uygulamalarında kurumlar arasında farklılıklar olması,

- Eğitime ilişkin standart bir programın olmaması, eğitimin amaç ve hedeflerinin, içeriğinin, uygulama yöntem ve tekniklerinin, değerlendirmelerinin yetersiz olması,

- TTE'nin emek olarak yoğun, lojistik olarak zor (ulaşım, konaklama, güvenlik, öğrenme materyalleri vb.), geleneksel eğitimden daha maliyetli olmas1,

- Uygulama alanlarının, öğrenme hedefleri açısından uygunluğunu değerlendirme ölçütlerinin yeterli olmamas1,

- Öğrencilerin gereksinimleri ve toplumun ihtiyaçları arasında uyuşmazlık olması,

- Öğrencilerin uygulama alanlarında kültürel (din, dil vb.) sorunlar yaşaması,

- Uygulama alanlarında TTE konusunda öğrencilere rehberlik edecek ve rol-model olacak nitelik ve sayıda eğitimcinin olmaması,

- TTE çalısmaları ile ilgili yeterli geribildirimin verilmemesi nedeniyle toplumun işbirliği konusunda şüpheci ve güvensiz olmas1,

- Toplumun aynı öğrenme deneyimleri açısından farklı kuruluşlar tarafindan tekrar tekrar kullanılmasının toplumda tükenmişliğe yol açması,

- Topluma sağlık bakım hizmeti sunan bazı kurum ve kuruluşların öğrencilerin eğitimi konusunda iş yükü nedeniyle kuruma kabulde gönülsüz davranmas1,

- Eğitimcilerin TTE ile ilgili çaba ve emeklerinin akademik çalışmalardan daha değersiz görülmesi olarak sıralanabilir (Linda ve ark, 2013; Mabuza ve ark, 2013; Kaye ve ark, 2011; Mtshali, 2011; Ervin ve ark, 2006). 


\section{Toplum Temelli Eğitim Uygulamalar}

Sağlık çalısanı yetiştiren hemen hemen tüm akademik kurumlar, topluma sunulan sağlık hizmetlerini temel görevlerinden biri olarak tanımlamaktadır. Buna rağmen topluma dayalı bakımda öğrencilere yeterince yer verilememesi süregelen bir sorundur. Başarllı bir TTE için akademik ortamların değişimi amacıyla yapılan girişimlerin yetersiz olduğu vurgulanmaktadır (Cauley ve ark, 2001; Davidson, 2002). Doran (2008), DSÖ’nün “Tıp fakülteleri eğitim, araştırma ve sağlık hizmetlerini, hizmet vermekle sorumlu olduğu toplumun öncelikli sağlık sorunlarına yönlendirmek zorundadır" diyerek tup fakültelerinde "Topluma Dayalı Tıp Eğitimi” anlayısıının benimsenmesi gerektiğini vurguladığını, oysa yine DSÖ tarafindan yapılan bir araştırmaya göre tıp fakültelerinin yalnızca \%1.5’inin kendi ülkelerindeki sağllk sorunlarına öncelik veren bir müfredata sahip olduklarını belirtmektedir. Yoder, Cohen ve Gorenberg (1998) de "Hemşirelik müfredatının toplum temelli uygulamalara entegre edilmesi artık bir seçim değildir" diyerek konunun hemşirelik eğitimindeki önemine dikkat çekmiştir (akt. Van Ort \& Townsend, 2000).

Sağlık çalışanlarının yetiştirilmesinde TTE, pek çok ülkede; Amerika Birleşik Devletleri (ABD), Avustralya, Filipinler, Güney Afrika Cumhuriyeti, İngiltere, Kanada, Küba, Nijerya, Mali gibi uygulanmaktadır (Kaye ve ark, 2011; Keck \& Reed, 2012). TTE uygulamalarının ülkelerdeki sağlık sistemine göre değişiklik gösterdiği ve genellikle iki şekilde uygulandığı görülmektedir:

1. Öğrencilerin TTE programlar doğrultusunda yetiștirilmesi: Bu uygulamada eğitim programları TTE'e uygun şekilde yapılandırmaktadır. Örnek olarak; ABD tarafindan mali olarak desteklenen Tip Eğitimi Ortaklığ 1 Girişimi (Medical Education Partnership Initiative -MEPI) programı çerçevesinde, Afrika ülkelerinde 25 tp fakültesinde ABD'deki üniversitelerle işbirliği içinde TTE programı uygulanmaktadır (Talib ve ark, 2013). Bu programın dişında TTE uygulayan üniversitelere örnek olarak Jimma Üniversitesi (Jimma University, t.y) ve Mekelle Üniversitesi (Mekelle University, t.y) verilebilir. Bir başka örnek de, Filipinler Üniversitesi Manila Sağlık Bilimleri Okulu'nda uygulanan (University of the Philippines, Manila School of Health Sciences) Sağlık Bakanlığı ve toplum işbirliği ile ebe, hemşire ve hekimlerin tek bir programla yetiştirildiği toplum ve yeterlik temelli eğitim programıdır (Siega-Sur, 2015). Küba'da da TTE birçok ülkeden çok daha önce, ülke genelinde sağlık sistemi içinde aile hekimliği ve hemşireliği uygulamasına entegre edilerek başarll bir şekilde kullanılmıştır (Keck \& Reed, 2012).

2. Ögrrencilerin eğitimleri surasında TTE projelerine katıllmmmn sağlanmas: TTE projeleri, mali destek, hedeflenen toplumun özellik ve ihtiyaçları, öğrenme hedefleri vb. bağlı olarak uzun dönemli projelerden, kısa dönemli projelere kadar değişiklik göstermektedir. Başarılı ve sürdürülen bir proje örneği, 1996 yllinda Philadelphia Toplum Koleji Hemşirelik Bölümü (Community College of Philadelphia Department of Nursing) tarafından hemşirelik öğrencileri için toplumun ihtiyaçları dikkate alınarak tasarlanan "19130 Zip Code Projesi” dir. Proje kapsamında, bu bölgede yaşayan toplumun sağlık ihtiyaç analizleri yapılmış ve sonuçlar doğrultusunda özellikle yaşlı nüfus ve kamu okullarında eğitim alan çocukların sağlık ihtiyaçlarına öncelik verilerek, hemşirelik öğrencileri için TTE programı yürütülmüştür. Proje sayıları zamanla artarak sürdürülmeye devam edilmektedir (Mengel \& Tagliareni, 2015). Bir başka örnek proje ise ABD'de Texas Üniversitesi Sağlık Bilimleri Merkezi (University of Texas Health Science Center at Houston - UTHSC-H) toplum sağllğı ve tip öğrencileri ile St. Mary's Birleşik Protestan Kilisesinin işbirliği ile 1999 yllinda genellikle AfroAmerikalıların yaşadığı bir bölgede HIV-AIDS ve madde kullanımının engellenmesi amacıyla başlatılan ve ihtiyaca yönelik olarak yeni alanların eklenerek yürütüldügüu, başarılı bir TTE ve araşurma projesidir (Marcus et al, 2011).

Ülkemizde TTE'nin önemi henüz yeteri kadar anlaşılamamıştır. Literatür incelendiğinde, ülkemizde sağlık insan gücü yetiştiren kurumların eğitim programlarında TTE'ye kısmen yer verildiği ancak TTE'ye dayalı eğitim programının olmadığı görülmüştür. 2015 yllında düzenlenen “Toplum Temelli Tıp Eğitimi, Mezuniyet Öncesinden Sonrasına” konulu 9. Tıp Eğitimi Çalıstayı bildiri raporunda tıp fakülteleri eğitim programlarının içeriğinin topluma yönelik, uygulama alanlarının ise topluma dayalı olarak düzenlenmesi gereğine dikkat çekilmiştir (TURKMSIC, 2015). 
Hemşirelik eğitimi programlarında ise Türkiye'de 2017 yllı itibari ile genel olarak klasik eğitim modeli başta olmak üzere entegre eğitim ve probleme dayalı öğrenme gibi farklı eğitim modelleri kullanılmaktadır (YÖK, 2017). Bu programlarda, sağlıktan hastalığa ve toplumdan bireye doğru bakım yaklaşımı benimsenmekte, eğitim programlarında topluma yönelik uygulamalar/stajlar yapılmakla birlikte eğitim programının TTE'ye temellendirildiği hemşirelik lisans programlarının olmadığ1 görülmektedir. 19.04.2011 tarihinde 27910 sayll yönetmelikte toplum temelli hizmet veren hemşirelerin (ana çocuk sağllğ̆1 ve aile planlaması hemşiresi, toplum ruh sağlığı hemşiresi, alkol ve madde bağımlılığı hemşiresi, iş sağlığı hemşiresi, okul sağllğı hemşiresi, ceza ve tutukevi hemşiresi, evde bakım hemşiresi) görev yetki ve sorumlulukları belirlenmiştir (http://www.resmigazete.gov.tr/eskiler/2011/04/20110419-5.htm Erişim: 29.06.2018). Aile hekimliği uygulama yönetmeliğinde aile sağlığı elemanları arasında hemşirenin görev tanımları yapılmıştır (http://www.mevzuat.gov.tr/Metin.Aspx?MevzuatKod=7.5.17051\&Mevzuatlliski=0\&sourceXmlSearch= $\quad$ Erişim:16.07.2018). 2023 yllı sağlık iş gücü hedefleri doğrultusunda, 315.000 hemşirenin 35.000 kadarının (\%10'dan fazlası) birinci basamakta, diğerlerinin hastanelerde istihdam edileceği tahmin edilmektedir (SB, 2014). Yukarıdaki bilgiler 1şığında görev ve istihdam alanları düşünüldüğünde hemşirelerin toplum temelli alanlarda aktif ve geniş ölçekte yer aldığ1 görülmektedir. TTE'de genellikle sınırlı/yetersiz sağlık hizmeti alan birey ve topluma odaklanılmaktadır. Ülkemizin yüz yüze kaldığ1 ciddi bir sorun olan göç ve göçmenlerin sağlık hizmeti ihtiyaçları (TTB, 2016), yaşlanan nüfus ve beraberinde getirdiği hastalık yükü (Aydın, 2014), kronik hastalıkların giderek artması ve sorunun çözümüne yönelik evde bakım modellerinin geliştirilmesi (Yılmaz ve ark, 2010), kronik hastalıkların yönetiminde birinci basamak odaklı ve toplum temelli hastalık yönetimi programlarının öneminin artması (İncirkuş \& Nahçivan, 2015), bakım ve tedavinin toplum temelli ortamlarda sürdürülmesini gerektirmektedir. Bu gereklilik de bu ortamlarda çalışacak nitelikte hemşire yetiştiren toplum temelli hemşirelik eğitim programlarını zorunlu kılmaktadır.

\section{Toplum Temelli Hemşirelik Eğitimi}

Sağlık çalışanlarının rol ve işlevleri, birey, aile ve topluma sağlıktan-hastalığa, tüm ortamlarda sağlık bakım hizmeti sunmayı gerektirir. Bu gereklilik, hemşirelik eğitimini hastane temeli eğitimden TTE'ye yönlendiren bir paradigma değişimini de beraberinde getirmektedir (Mtshali, 2011). Toplum temelli hemşirelik eğitimi, hemşirelik öğrencilerinin bireylerin olduğu her yerde, birey ve aile merkezli hemşirelik bakımı vermeyi öğrendiği (Hunt, 2013; Nambozi \& Locsin, 2017; Zotti ve ark, 1996), klinik eğitimin hastanelerden çok toplumun olduğu her ortamda uygulandığı, farklı öğrenme ortamları ve stratejileri sunan yenilikçi bir eğitimdir (Carter ve ark, 2005). Toplum temelli hemşirelik, hemşirelikte bir uzmanlık alanı değil tüm hemşirelik uzmanlık alanlarına rehberlik eden bir felsefedir (Zotti ve ark, 1996). Öğrencilere toplum temelli hemşirelik felsefesini kazandırmanın yolu onları topluma yönelik öğretim programları ile yetiştirmek, "toplumu dersliğe getirmek" yerine "dersliği topluma götürmek" "toplumu derslik olarak benimseyerek" öğrenim yaşantılarının gerçekleştirilmesidir. Tüm deneyimini hastanede edinen, sürekli "hastalarr" gören bir hemşirenin "iyilik" durumunu değerlendirme, tanı koyma, bağımsız kararlar alma, hastayı çevresi ile bir bütün olarak değerlendirme, özgüven, karar verme ve bütüncül yaklaşım gibi becerileri geliştirmesi güçtür (Baylk, 1988).

TTE'de hemşirelik öğrencilerinin genellikle kırsal bölgelerde yetersiz sağlık hizmeti alan bireylere nitelikli sağlık hizmeti sunabilmesi için gerekli bilgi, beceri ve tutum kazanması, sosyal ve çevresel faktörlerin sağllğa etkilerini kavraması, sağlığı koruma/geliştirme anlayışı ve araştırma becerisi geliştirmesi amaçlanır. Öğrenciler, toplum ortamlarında genellikle uygulamalı öğrenme yöntemleri ile halk sağlığı, klinik uygulama ve araştırma becerileri edinirler. Hemşirelik girişimleri birey, aile ve toplumun değerleri doğrultusunda birey, aile ve sağlık ekibi üyeleri tarafindan belirlenir. TTE ile öğrenciler, multidisipliner bir ekibin üyesi olarak kaynaklan yetersiz bu alanlarda çalışmaya hazırlanırlar (Nambozi \& Locsin, 2017; Hunt, 2013). 


\section{Toplum Temelli Hemşirelik. Ë̈̆tim Programmmn Temel Öz̨ellikleri Neler Olmalidır?}

Hemşirelik eğitim programları, değişen sağlık sistemine uyum sağlayacak, sorun çözme becerileri gelişmiş, yaşam boyu öğrenmeyi benimseyen, toplumun var olduğu tüm alanlarda sağllk bakım hizmeti verebilen öğrenciler yetiştirecek şekilde düzenlenmelidir (Ervin ve ark, 2006). Toplum temelli hemşirelik eğitim programı hazırlanırken öncelikle ulusal sağllk ve eğitim politikaları, toplumun öncelikli sağllk sorunlan ve öğrencinin öğrenme gereksinimleri dikkate alınmalıdır (Mtshali, 2009). TTE programı geliştirirken eğitimciler, sağlık çalışanları, toplum liderleri, yöneticiler, öğrenciler ve toplumu oluşturan bireylerin görüşleri alınmalıdır. Program eğitimciler, program geliştirme uzmanları, dekan ve yöneticiler tarafindan oluşturulmalıdır (Carter ve ark, 2005). TTTE'nin başarlı bir şekilde uygulanması ve sürdürülmesi için hemşirelik eğitim kurumları, toplum ve sağlık hizmet sektörü arasındaki işbirliğinde tarafların rol ve sorumlulukları belirlenmelidir (Mtshali, 2009).

TTE programları kapsamında öğrenciler, oryantasyon eğitimleri ile kültürel farklılıklar, grup dinamikleri, topluma giriş, toplum katılımı, hızlı değerlendirme ve epidemiyolojik çalışmaların nasıl yapılacağ1, öz-yönelimli öğrenmenin geliştirilmesi gibi konularda bilgilendirilmelidir. TTE genellikle kaynaklara yeteri kadar ulaşamayan, hastalıkların olduğu ve dezavantajlı grupların yaşadığı bölgelerde uygulandığı için öğrenci ve aileleri tarafindan güvensiz ortamlar olarak algılanmaktadır. Bu algının değiştirilmesi için öğrenci ve ailelerine yönelik bilgilendirme toplantıları yapılmalıdır (Mtshali, 2009).

TTE uygulamalarında yer alan eğitimciler; danışmanlık/rehberlik, öğrencileri aktif öğrenme için cesaretlendirme, toplumu TTE'ye hazırlama, toplumun öğrenilecek yanlarını ve kaynaklarını seçme, toplumla görüşmeler ve ortaklıklar başlatma-sürdürme, gerektiğinde alternatif çözümler üretebilme, eleştirel düşünme, yenilikçi, yaratıcı ve araştırmacı olma gibi nitelikler taşımalıdır. TTE uygulamalarında yer alan öğrenciler; toplumun ihtiyaçları doğrultusunda program içeriği oluşturma sürecine aktif katılmalı, sınırlı kaynaklara sahip bölgelerde hizmet vermeye istekli olmalı, TTE'yi sosyal değişim için bir güç olarak görmeli ve değişim ajanı olarak aktif rol almalıdır (Mtshali, 2009, Owens \& Wang, 1996).

TTE eğitim programı hazırlanırken izlenecek adımlar şunlardır:

- Tüm paydaşların katılımı ile ortak misyon, vizyon ve eğitimin amaçları oluşturulmalıdır.

- TTE uygulaması yapılacak toplum, öğrenme ihtiyaçları ve toplum gereksinimleri dikkate alınarak belirlenen hedefler doğrultusunda seçilmelidir.

- Öğrenci-toplum karşılaşması eğitim programında mümkün olduğu kadar erken (1. ve 2. yılda) ve öncelikli olarak halk sağlı̆̆1 merkezlerinde olmalı, ders içerikleri ve uygulamalarında, sağlıktan hastalığa doğru bir sıra izlenmelidir.

- Beklenen mezun yeterlilikleri, topluma tüm basamaklarda (birinci, ikinci, üçüncü basamak sağlık kuruluşları, rehabilitasyon merkezleri vb.) hizmet verebilir nitelikte olmalıdır.

- Öğrenme deneyimleri, öğrenme hedefleri ile örtüşmelidir.

- Öğrencilerin analitik ve eleştirel düşünme, problem çözme, iletişim becerilerini ve ekip çalışması vb. özelliklerini geliştiren yaparak-yaşayarak öğrenme, işbirlikçi öğrenme ve özyönelimli öğrenme gibi aktif öğrenme yöntemleri kullanılmalıdır. Aynı zamanda hizmet içi eğitim, iş-temelli öğrenme ve takım çalışması gibi eğitimlerle öğrencilerin öğrenme deneyimleri zenginleştirilmelidir.

- TTE uygulamalarının, öğrencilerin ve toplumun gereksinimlerini ne ölçüde karşıladığı ve programın etkinliği değerlendirilmeli, izlenmeli ve sonuçlar doğrultusunda eğitim programları güncellenmelidir (Ervin ve ark, 2006; Mtshali, 2005; Mtshali, 2009) 


\section{Sonuç ve Öneriler}

TTE, sağlık profesyonellerinin yaşadığı toplumun ihtiyaçlarını fark ederek bu ihtiyaçları karşılama yeterliliğini geliştirmeye odaklanır. Öğrencilerin bilgiyi kullanma, problem çözme, kişiler arası ilişkiler, yaratıcılık vb. bilişsel, duyuşsal ve sosyal yönlerinin gelişimini amaçlar. Sağlık çalışanlarının TTE programları ile yetiştirilmesi ile sınırlı kaynakları olan toplumlarda sağlığın geliştirilmesi ve hastalıkların önlenmesine etki edilebilir. Bireylerin sağlıklı yaşam biçimleri geliştirmesi, kronik hastalıklarla mücadele ya da kronik hastalığ yönetme becerileri anlamlı ölçüde arttırılabilir. Hızla yaşlanan toplumun ihtiyaçlarına etkili çözümler sunulabilir. Bu şekilde toplumun refah düzeyi artarken öğrencilerin öğrenmeleri de güçlendirilip geliştirilebilir. TTE, eğitim kurumları ve öğrencilere toplumsal verilere dayanarak bilime katkıda bulunan keşifler yapma olanağ1 sağlayabilir.

TTE'nin uygulandığı ülkelerde, TTE'nin hemşirelik eğitimine etkileri, müfredat planlaması ve uygulamaları, toplum ve paydaşlara etkileri konusunda yapılan çalışmalar yakından izlenerek, Türkiye'de TTE müfredatını temel alan hemşirelik programları tasarlanmalıdır. Üniversitelerdeki bazı hemşirelik eğitim programları TTE müfredatına göre yapılandırılabilir. Başlatılan programlar, uygulamaların başarısına göre yaygınlaştırılabilir. TTE konusunda tüm paydaşların bilgilendirilerek geleceğin sağlık profesyonellerinin yetiştirilmesinde üzerine düşen sorumluluğun farkında olması ve bu misyona katkıda bulunması sağlanmalıdır.

\section{Kaynaklar}

Amalba, A., Mook, W.N.K.A.V., Mogre, V. \& Scherpbier, A.J.J.A. (2016). The perceived usefulness of community based education and service (COBES) regarding students' rural workplace choices. BMC Medical Education, 16:130. https://doi.org/10.1186/s12909-016-0650-0

Aydın, S. (2014). Yaşlanan Türkiye’ye sağlık politikası üretmek. Sağhlk Düs̆̈̈ncesi ve Tip Kültürü Dergisi, 32: 48-53.

Bayık, A. (1988). Halk sağlı̆̆ hemşireliği uygulamalarında öğrencilerin öğrenim yaşantıları ve öğretinin konusuna ilişkin değerlendirmeleri. Ege Üniversitesi Hemsirelik Yülesek Okulu Dergisi $4: 1$.

Bellack, J.P. (1998). Community-based nursing practice: Necessary but not sufficient. Journal of Nursing Education, 37(3): 99.

Bor, D. (2003). Position Paper on Community-Based Education for Health Professionals. Education for Health,16(3): 400-403.

Carter, K.F., Fournier, M., Grover, S., Kiehl, E.M \& Sims, K.M. (2005). Innovations in Community-Based Nursing Education: Transitioning Faculty. Journal of Professional Nursing, 21(3): 167-174. https://doi.org/10.1016/i.profnurs.2005.04.004

Cauley, K., Canfield, A., Clasen, C., Dobbins, J. Hemophill, S., Jaballas, E.,Walbroehl, G.(Community-Campus Partnerships for Health). (2001). Service learning: Integrating student learning and community service. Educ Health (Abingdon), 14(2):173-81. DOI: $10.1080 / 13576280110057563$

Davidson, RA. (2002). Community-based education and problem solving: The community health scholars program at the University of Florida, Teaching and Learning in Medicine, 14(3):178181. https://doi.org/10.1207/S15328015TLM1403 8

Dickson, CA., Morris, G. \& Gable, C. (2015). Enhancing undergraduate community placements: a critical review of current literature. British Journal of Community Nursing, 20(4): 184-9 https://doi.org/10.12968/bjen.2015.20.4.184

Doran, F. (21.04.2008 Pazartesi). Topluma dayalı tıp eğitiminin gerekçeleri.

http://www.medimagazin.com.tr/authors/figen-doran/tr-topluma-dayali-tip-egitiminingerekceleri-72-75-1605.html 
Ulupınar, S., Gürel, E., Șenyuva, E., \& Kaya, H. (2019). Toplum temelli hemșirelik eğitimi. Journal of Human Sciences, 16(3), 700-711. doi:10.14687/jhs.v16i3.5514

Edwards, H., Smith, S., Courtney, M., Finlayson, K. \& Chapman, H. (2004). The impact of clinical placement location on nursing students' competence and preparedness for practice. Nurse Education Today, 2004; 24(4): 248-255. http://dx.doi.org/10.1016/j.nedt.2004.01.003

Ervin, N.E., Bickes, J.T., Scim, S.M. (2006). Environments of Care: A Curriculum Model for Preparing a New Generation of Nurses. Journal of Nursing Education, 45(2): 75-80.

Hamad, B. (1991). Community-oriented medical education: what is it? Medical Education, 25:16-22

Harden R.M., Sowden S. \& Dunn, W.R. (1984). Educational strategies in curriculum development: the SPICES model. Medical Education, 18, 284-97.

Hosny, S., Kamel, M.H., El-Wazir, Y. \& Gilbert, J. (2013). Integrating interprofessional education in community-based learning activities: Case study. Medical Teacher, 35:(1):68-73 https://doi.org/10.3109/0142159X.2013.765550

Howe, A. (2002). Twelve tips for community-based medical education Twelve tips for communitybased medical education. Medical Teacher, 24(1)

Hunt, R. (2013). Introduction to Community-Based Nursing. 5th Edition. Wolter Kluwer / Lippincott Williams \& Wilkins.

İncirkuş, K. \& Nahçivan. N.Ö. (2015). Kronik Hastalık Yönetimi İçin Bir Rehber: Kronik Bakım Modeli. F.N. Hem. Derg. 23(1): 66-75

Jimma University. (t.y). Community. https://www.ju.edu.et/community?q=community Erişim: 01.08.2018

Jimma University. (2013). Guidelines and Procedures for Community Based Education. https://www.ju.edu.et/sites/default/files/Procedures $\% 20$ and $\% 20$ Guidelines $\% 20$ for $\% 20$ CBE.pdf Erişim: 01.08.2018

Kaye, D., Mwanika, A., Burnham, G., Chang, L.W., Mbalinda, SN., Okullo, I. et al. (2011). The organization and implementation of community-based education programs for health worker training institutions in Uganda. BMC International Health and Human Rights, 11(1):4. https://doi.org/10.1186/1472-698X-11-S1-S4

Kelly, L., Walters, L. \& Rosenthal, D. (2014). Community-based medical education: Is success a result of meaningful personal learning experiences? Educ Health, 27:47-50 doi: 10.4103/1357-6283.134311

Keck, C.W \& Reed, G.A. (2012). The Curious Case of Cuba. Am J Public Health, 102(8): e13-e22. DOI: 10.2105/AJPH.2012.300822

Linda, N.S.B., Mtshali, N.G. \& Engelbrecht, C. (2013). Lived experiences of a community regarding its involvement in a university community-based education programme. Curationis, 36(1):1-13 http://dx.doi.org/10.4102/curationis.v36i1.78

Mabuza, L., Diab, P., Reid, S., Ntuli, B., Flack, P., Mpofu, R. et al. (2013). Communities' views, attitudes and recommendations on community-based education of undergraduate Health Sciences students in South Africa: A qualitative study. African Journal of Primary Health Care \& Family Medicine, 5 (1): 1-9 https://doi.org/10.4102/phcfm.v5i1.456

Marcus, M.T., Taylor, W.C., Hormann, MD., Walker, T. \& Carroll, D. (2011). Linking servicelearning with community-based participatory research: An interprofessional course for health professional students. Nursing Outlook, 59(1):47-54. http://dx.doi.org/10.1016/j.outlook.2010.10.001

Mekelle University. (t.y). Community Based Education.

http://www.mu.edu.et/chs/index.php/research-and-community-services/communityservices/community-based-education-cbe Erişim: 06.08.2018

Mengel, A. \& Tagliareni, ME. (2015). The 19130 Zip Code Project: A Journey to Our Neighborhood. Hansen-Turton, T., Sherman, S \& King, ES. (Ed.) Nurse-Led Health Clinics: Operations, Policy, and Opportunities içinde (193-202) USA. Splinger Publishing Company. 
Ulupınar, S., Gürel, E., Şenyuva, E., \& Kaya, H. (2019). Toplum temelli hemşirelik eğitimi. Journal of Human Sciences, 163), 700-711. doi:10.14687/jhs.v16i3.5514

Mtshali, N.G. (2005). Conceptualisation of community-based basic nursing education in South Africa: a grounded theory analysis. Curationis, 28(2): 5-12. https://doi.org/10.4102/curationis.v28i2.939

Mtshali, N.G. (2009). Implementing community-based education in basic nursing education programs in South Africa. Curationis, 32(1): 25-32.

Mtshali, N.G. (2011). The emergence of community-based nursing education programmes in South Africa. Journal of Community \& Health Science, 6(2): 18-26.

Mtshali, N.G.\& Gwele, N.S. (2016). Community-based nursing education in South Africa: A grounded-middle range theory. Journal of Nursing Education and Practice, 6(2):55-67. https://doi.org/10.5430/inep.v6n2p55

Nambozi \& Locsin, 2017. Community-based pedagogy of nursing in developing countries; An integrative review. Journal of Nursing Education and Practice, 7(1): 51-61. http://dx.doi.org/10.5430/jnep.v7n1p51

Okayama, M. \& Kajii, E. (2011). Does community-based education increase students' motivation to practice community health care? - a cross sectional study. BMC Medical Education, 11:19. https://doi.org/10.1186/1472-6920-11-19

Oneha, M.F., Yoshimoto, C.M., Bell, S. \& Enos, R.N. (2001). Educating health professionals in a community setting: What students value. Education for Health, 14(2):256-66.

Owens, TR. \& Wang, C. (1996). Community-based learning: A foundation for meaningful education reform. Service Learning, General. Paper 37. https://digitalcommons.unomaha.edu/cgi/viewcontent.cgi?article $=1043 \&$ context $=$ slceslge n Erişim: 10.07.2018

Proctor, P., Lake, D., Jewell, L., Racine, L., D’Eon, M. \& Reeder, B. (2010). influencing student beliefs about poverty and health through interprofessional community-based educational experiences. Journal of Research in Interprofessional Practice and Education (JRIPE), 1(2): $145-158$.

Siega-Sur, J.L. (2015). Skill sets and pedagogy. Cuff, P.A.(Rapporteur). Global forum on innovation in health professional education; board on global health; Institute of Medicine. Building health workforce capacity through community-based health professional education: Workshop Summary. Washington (DC): National Academies Press (US) https://www.ncbi.nlm.nih.gov/books/NBK293680/ Erişim 10.07.2018

Talaat, W., Khamis, N. \& Aziz, AA. (2011). Ten frequently asked questions on communityoriented/based medical education. Med. J. Cairo Univ, 79 (2): 55-60.

Talib, Z.M., Baingana, R.K., Sagay, A.S, Van Schalkwyk, S.C, Mehtsun, S., Kiguli-Malwadde, E. (2013). Investing in community-based education to improve the quality, quantity, and retention of physicians in three African countries. Educ Health (Abingdon), 26(2):109-114. doi: 10.4103/1357-6283.120703

T.C.S.B. Sağlık Hizmetleri Genel Müdürlüğü (2014). 2023 Yılı Sağlık İş Gücü Hedefleri ve Sağlık Eğitimi.

Türk Tabipler Birliği (TTB). (2016). Savaş, Göç ve Sağlık. Türk Tabipleri Birliği Yayınları. Ankara. http://www.ttb.org.tr/kutuphane/siginmacilar rpr.pdf Erişim: 06.07.2018

Türk Tip Öğrencileri Birliği (TURKMSIC) (2015). 9. Tıp eğitimi çalıştayı bildirisi. "Toplum temelli tup eğitimi, mezuniyet öncesinden sonrasına"

http://turkmsic.net/sites/default/files/bildiriler/9.tip egitimi calistayi sonuc bildirisi.pdf Erişim: 05.04.2018

Van Ort, S. \& Townsend, J. (2000). Community-based nursing education and nursing accreditation by the commission on collegiate. Nursing Education Journal of Professional Nursing, 16(6): 33035.

Villani, C.J \& Atkins, D. (2000). Community-Based Education. School Community Journal, 10(1):121126. 
Ulupinar, S., Gürel, E., Şenyuva, E., \& Kaya, H. (2019). Toplum temelli hemşirelik eğitimi. Journal of Human Sciences, 16(3), 700-711. doi:10.14687/jhs.v16i3.5514

WHO (1987). Community-based education of health personnel. WHO Study Group. Technical Report Series. 746. Geneva. Switzerland

Wink, D.M. (2003) Community-Based Cirricula at BSN and Graduate Levels. Oerman, M.H \& Heinrich, K.T.(Eds). in Annual Review of Nursing Education (s:4-26). 1. Cilt. Springer Publishing Company. USA

Yılmaz, M., Sametoğlu, F., Akmeşe, G., Tak, A., Yağbasan, B., Gökçay, S., Sağlam, M., Doğanyılmaz, D. \& Erdem, S. (2010). Sağlık hizmetinin alternatif bir sunum şekli olarak evde hasta bakımı. İstanbul Tip Derg, 11(3):125-132.

Yükseköğretim Kurulu (YÖK). (2017). Hemşirelik lisans eğitimi çalıştay raporu. http://www.yok.gov.tr/web/guest/hemsirelik-lisans-egitimi-calistay-raporu-yayimlandi Erişim: 10.05.2018

Zotti, ME., Brown, P. \& Stotts, R. (1996). Community-based nursing versus community health nursing: what does it all mean? Nursing Outlook, 44(5): 211-217.

\section{Extended English Summary}

The goals of the training are to educate the individual and the profession members for; to define and analyze problems by evaluating the physiological, psychological, sociological, environmental and political dimensions of the society and to develop realistic and feasible solutions, to apply, to evaluate and if it is necessary to make changes according to the results. One of the most effective approaches to train individuals with qualifications that are appropriate to these goals and have developed critical thinking and organizational skills is community-based education. Community-based education (CBE) is an educational model which gives the opportunity to use academic knowledge and skills in real life situations to the learners, carrying out their learning experiences outside the classroom while meeting the needs of the community. At the same time in this model, the coordination of learning experiences cooperates with the educational institutions and the community together. Learning experiences in CBE take place in community settings. The learning environment is everywhere that people lives (urban, rural, etc.). Educators, students, community members, service providers and representatives of institution actively participate in the implementation of training programs (Owens \& Wang, 1996; Carter et al., 2005; Mekelle University, n.d, WHO, 1987).

The roles and functions of health professionals necessitate providing health care services in all sorts of settings to individuals, families, and communities in any case from health to illness. This necessity has contributed significantly to the paradigm shift from hospital-based education to community-based education in nursing education (Mtshali, 2011). Yoder, Cohen \& Gorenberg (1998) emphasize the significance of the curricular changes in nursing education when they state, "transforming the nursing curriculum to incorporate practice in community-based sites is no longer a choice" (Van Ort \& Townsend, 2000). Nursing students must learn to give individual and familycentered nursing care, in everywhere that individual and community take place in (Carter et al., 2005; Hunt, 2013; Nambozi \& Locsin, 2017; Zotti, Brown \& Stotts, 1996). CBE is an innovative education which provides different learning environments and strategies that clinical education where applied in more community settings than hospitals (Carter et al., 2005; Hunt, 2013; Nambozi \& Locsin, 2017; Zotti, Brown \& Stotts, 1996).

$\mathrm{CBE}$ focuses on individuals and community who generally take inadequate healthcare. Care and treatment should be carried out in community-based settings because of reasons such as increasing immigration and immigrants' health care needs in our country (TTB, 2016), old age and accompanying illness burden (Aydin, 2014), development of home care models for solution to increasing chronic diseases (Y1lmaz et al., 2010), the increase in the importance of primary care and community-based disease management programs (İncirkus \& Nahcivan, 2015). This necessity also necessitates community-based nursing education programs that provide nurses with the 
qualifications to work in these settings.

Nursing education programs should be planned in such a way that students will be able to adapt to the changing healthcare system, develop problem-solving skills, adopt lifelong learning, and also who can provide health care services in all areas where the community exists (Ervin, Bickes, \& Scim, 2006). When designing a community-based nursing education program, it should be considered firstly national health policies, national education policies, priority health problems of the community and learning needs of the learners (Mtshali, 2009).

While the CBE program is developing, it must be considered the views of educators, students, health workers, and individuals who constitute the community. The education program should be developed by experts, educators, curriculum committees, deans, and administrates (Carter et al, 2005). The roles and responsibilities of the parties in the co-operation between the nursing education institutions, the community, and the health service sector should be determined for the successful implementation and sustainability of the CBE.

CBE's curriculum should be designed by closely monitoring the studies about the effects of $\mathrm{CBE}$ to nursing education, community and the other stakeholders, curriculum planning and implementation in countries where $\mathrm{CBE}$ is applied. Some nursing education programs in universities can be structured in according to the CBE curriculum. Initiated programs can be dissemination according to the success of the practice. The community should be informed about $\mathrm{CBE}$ so that it can be provided that each individual is aware of their responsibilities in the training of future health professionals and contribute to this mission.

The main purpose of the review is to explain the importance and necessity of communitybased nursing education programs in order to train qualified nurses for the needs of the community and the basic features of a community-based nursing program. The concepts of community-based education and community-based nursing education have been extensively e valuated. CBE program applications, the strengths of community-based education, the difficulties in implementation, the basic principles to be considered when preparing a community-based education program, have been scrutinized by the literature review and the data of countries that have experience about CBE. 